Original Research Article

\title{
Spectrum of adverse drug reactions and implicated drugs in a tertiary care centre: a prospective study
}

\author{
Kabilan K.*, Sathyanarayanan V., R. Jammuna Rani
}

Department of Pharmacology, SRM Medical College Hospital and Research Centre, SRM Nagar, Kattankulathur, Tamil Nadu 603203, India

Received: 22 April 2018

Accepted: 23 May 2018

\section{*Correspondence to:}

Dr. Kabilan K.,

Email: manjrekhadmbbs@ gmail.com

Copyright: (C) the author(s), publisher and licensee Medip Academy. This is an openaccess article distributed under the terms of the Creative Commons Attribution NonCommercial License, which permits unrestricted noncommercial use, distribution, and reproduction in any medium, provided the original work is properly cited.

\begin{abstract}
Background: Adverse Drug Reaction(ADR) is the major limitation in providing health care to patients at a global level. It affects patient's recovery and is an important cause of mortality and morbidity in both hospitalized and ambulatory patients. ADR can occur with any class of drugs. Early detection and evaluation of ADR is essential to reduce harm to the patients. Thus, the present study was aimed to estimate the number of ADR's reported, analyze its spectrum and the drugs attributed to it.

Methods: This was a prospective study conducted in a tertiary care teaching hospital for a period of 3 months from March 2016 to May 2016 in SRM Medical College and Hospital, Potheri. Adverse drug reactions were collected by spontaneous reporting by active and passive methods. The causality assessment of the reported ADR's was done using Naranjo causality assessment scale.

Results: A total of 38 ADR's were reported during the study period with male predominance $(58 \%)$. Most of the ADR's (42\%) were common in patients in the age group 19-39 years. More number of ADR's were from Medicine (29\%) followed by Surgery (16\%) and OG (16\%) departments. Most commonly affected organ systems were skin $(45 \%)$ followed by GIT $(24 \%)$. The drugs mostly accounted were antibiotics (55\%) especially Cephalosporins (33\%). Most of the reactions were type A (68\%) rather than type B (32\%) and thus predictable. According to Naranjo's causality assessment, 63\% of reactions were probable, $26 \%$ were possible and $11 \%$ were definite. No reactions were unlikely. Severity assessment by Modified Hartwig and Seigel scale revealed 45\% ADRs to be moderate, $42 \%$ were mild and $13 \%$ were severe and life threatening.

Conclusions: The study concluded that Adverse Drug Reactions are common and some of them resulted in increased healthcare cost due to need of some interventions and increased length of hospital stay. As majority of ADR is predictable (Type A), so preventable. The health system should promote the spontaneous reporting of Adverse Drug Reactions (May be done mandatory). The proper documentation and periodic reporting to regional pharmacovigilance centres to ensure drug safety.
\end{abstract}

Keywords: Adverse Drug Reactions, Causality, Pharmacovigilance, Spectrum, Spontaneous reporting

\section{INTRODUCTION}

Medicines are the most common medical interventions to relieve sufferings but as said rightly "drugs are double edged weapons" with a potential to cause benefit as well as harm. ${ }^{1}$ The most crucial step for safe use of drugs in humans is to prevent the occurrence of an adverse drug reaction (ADR). An ADR has been defined by the WHO as "any unintended and noxious response to a drug which occurs at doses normally used in human beings for the 
prophylaxis, diagnosis or therapy of disease, or for the modification of physiological function. ${ }^{2}$ " ADR is a dominant and preventable public health issue. It is also major limitation in providing in providing health care to patients at a global level. In India, the overall incidence of ADR ranges between $1.8 \%$ and $25.1 \%$, with $8 \%$ resulting in hospitalization. It also occurs in $10-20 \%$ of hospitalised patients. It is an inevitable consequence of drug therapy, as no pharmacotherapeutic agent is completely safe and more than $50 \%$ of approved drugs are associated with some type of adverse effects that are not detected prior to their approval for clinical use. ${ }^{3}$ Even though ADRs are implicated as seventh common cause of death and up to $57 \%$ of them being unrecognized by attending physicians, the data remain limited and inconsistent.

There are various factors such as age, gender, ethnicity, genetic factors, polypharmacy, drug interactions, multiple and inter-current diseases, increased length of hospital stay, dietary and environmental factors that contributes to increased occurrence of ADRs. It affects patient's recovery and is an important cause of mortality and morbidity in both hospitalized and ambulatory patients. ${ }^{4}$ Therefore, early detection and evaluation of ADR is essential to reduce harm to the patients. Also introduction of newer drugs in the market has been increased in the last two to three decades. Hence it is crucial to monitor both known and unknown side effects of the drugs.

World health organization-Upsala monitoring centre (WHO-UMC), the two principal collaborating bodies started pharmacovigilance programme to keep a watch on various ADRs and events occurring worldwide. Realizing the significance of monitoring ADRs to improve public health, Pharmacovigilance Programme of India (PvPI) was started in 2010. According to this program, ADR monitoring centers have been set up in many medical institutions all over the country to estimate the frequency of ADRs occurring with various drugs among the Indians. ${ }^{5}$ Spontaneous reporting of ADRs voluntarily by the healthcare professionals has been the core data-generating system of pharmacovigilance for years. It plays a major role in identifying and reporting of any adverse events to the pharmacovigilance coordinating center, health/regulatory authority or to the drug manufacturer itself. $^{6}$

The main drawback of this system by health care professionals (HCP) is under-reporting and selective reporting, which leads to a false conclusion about drug risk. ${ }^{4}$ ADR reporting and monitoring activities are of vital importance for patient safety, which can generate valid data regarding causality association, preventability and severity of ADRs in the human population. This study was therefore designed to evaluate incidence and the patterns of ADRs from the reports collected from various clinical departments of this hospital and to establish the causal link between the suspected drug and the reaction by using the causality definitions.

\section{METHODS}

This was a prospective study, which was carried out in the Department of Pharmacology, pharmacovigilance unit of Adverse Drug Monitoring Centre (AMC), SRM Medical College and Hospital, Potheri. Institutional Ethical Review Board approval was obtained before starting the study. The Department of Pharmacology, SRM is the regional ADR monitoring center under PvPI. The reports were collected from both inpatient and outpatient departments of hospital for suspected ADRs. Data was collected using structured format as per CDSCO ADR reporting form.

\section{Study design}

This was a prospective cross-sectional study conducted utilizing collection of spontaneously reported ADR data for a period of 3 months from march to May 2016. All the suspected ADR's due to medications taken either as inpatients or outpatients irrespective of age and sex were taken into account. Patients with drug reaction due to deliberate or unintentional over dosage, alternate medicine systems such as Ayurveda, Homeopathy, and Unani, prescribing and dispensing error reactions due to blood and blood products, admitted due to alcohol or drug abuse, mentally retarded or unconscious patients were excluded from the study. Discretion of information acquired was secured and all the measures to maintain confidentiality were undertaken, during the study.

\section{Study procedure}

Data of spontaneously reported ADRs for each patient by HCP were collected. Data on demographic details for patient profile (age and sex), prescribed medications (generic name of the medicine, dose frequency, strength, date of start and stop) were evaluated.

ADRs were evaluated with respect to description of the adverse event, onset and end of the adverse event, seriousness and information on de-challenge. The causality was assessed with the help of Naranjo ADR probability scale. Severity was assessed by Modified Hartwig and Siegel Scale. Preventability was assessed by Modified Schumock and Thornton Scale.

\section{Statistical analysis}

The data were entered in Microsoft Excel. They were analyzed using descriptive statistics namely mean and standard deviation for quantitative variables and the percentages as applicable for age, gender, causative drug, seriousness, severity, and causality. SPSS V16 statistical software was used to generate graphs and tables wherever necessary. All multiple responses are reported in terms of percentages and total of such response will be greater than sample size. 


\section{RESULTS}

The total of 38 ADRs were reported during the 3-month study period from 38 patients.

Most of the patients $(n=16)$ were in the age group of 19-39 years $(42 \%)$. Six patients were above 60 years in age, 12 patients were aged between40-59 years, 16 patients were aged between 19-39 years and 4 patients were aged less than 18 yrs. Higher incidence of ADRs was observed in male patients $(n=22)$ when compared to females $(n=16)$ (Table 1).

Table 1: Age and gender wise distribution of ADR.

\begin{tabular}{|lll|l|}
\hline Age range & Male & female & $\begin{array}{l}\text { Total } \\
\text { patients }(\%)\end{array}$ \\
\hline $1-18$ & 2 & 2 & $4(11 \%)$ \\
\hline $19-39$ & 7 & 9 & $16(42 \%)$ \\
\hline $40-59$ & 7 & 5 & $12(32 \%)$ \\
\hline Greater than 60 & 6 & 0 & $6(16 \%)$ \\
\hline Total patients & 22 & 16 & 38 \\
\hline
\end{tabular}

The reported ADR's in the study patients are depicted in Table 2. Rashes were the most common reported ADR followed by GIT disturbances like diarrhoea and vomiting. Most of the reactions were type A $(68 \%)$ rather than type B $(32 \%)$ and thus predictable. Parenteral administration of drugs produced large incidence of ADR $(74 \%)$ rather than oral administration (26\%). Figure 1 describes the organ systems involved in ADRs. The most common organ system affected was skin, accounting for $41 \%$ of total ADRs.

Table 2: Types of ADR reported.

\begin{tabular}{|ll|}
\hline ADR & Number reported (\%) \\
\hline Rashes & $14(34 \%)$ \\
\hline Urticaria & $3(7 \%)$ \\
\hline Diarrhea & $7(17 \%)$ \\
\hline Vomiting & $2(5 \%)$ \\
\hline Generalized hypersensitivity & $5(12 \%)$ \\
\hline Pedal edema & $3(7 \%)$ \\
\hline Lab abnormalities & $2(5 \%)$ \\
\hline Jaundice & $1(2 \%)$ \\
\hline Palpitation & $1(2 \%)$ \\
\hline Headache & $1(2 \%)$ \\
\hline Breathlessness & $1(2 \%)$ \\
\hline Thrombophlebitis & $1(2 \%)$ \\
\hline
\end{tabular}

Table 3: Drugs implicated in ADR.

\begin{tabular}{|c|c|c|c|c|}
\hline Drug group & & Name of the drug & Route & Number of ADRs \\
\hline \multirow[t]{14}{*}{ Antimicrobials 21(55\%) } & Cephalosporins 7(33\%) & Cefotaxime & IV & 4 \\
\hline & & Ceftrioxone & IV & 2 \\
\hline & & Cefaperazone & IV & 1 \\
\hline & Quinolones & Ofloxacin & $\mathrm{PO}$ & 2 \\
\hline & & Ciprofoxacin & $\mathrm{PO}$ & 1 \\
\hline & Pencillin group $6(29 \%)$ & Pencillin & IV & 2 \\
\hline & & Amoxicillin & IV & 2 \\
\hline & & Augmentin & IV & 1 \\
\hline & & Piperacillin & IV & 1 \\
\hline & Others & Aithromycin & $\mathrm{PO}$ & 1 \\
\hline & & Septran & $\mathrm{PO}$ & 1 \\
\hline & & Linezolid & IV & 1 \\
\hline & & Metrogyl & IV & 1 \\
\hline & & Amikacin & IV & 1 \\
\hline \multirow[t]{2}{*}{ Analgesics $6(16 \%)$} & & Diclofenac & IM/PO & 4 \\
\hline & & Paracetamol & $\mathrm{PO}$ & 2 \\
\hline \multirow[t]{3}{*}{ Anti cancer drugs } & & Oxaliplatin & IV & 1 \\
\hline & & Carboplatin & IV & 1 \\
\hline & & Adriamycin & IV & 1 \\
\hline \multirow[t]{3}{*}{ Enzymes } & & Hepamerz & IV & 1 \\
\hline & & Pancrealipase & $\mathrm{PO}$ & 1 \\
\hline & & Cerebroprotein Hydroxylate & IV & 1 \\
\hline Haematinics & & Hemfer & IV & 1 \\
\hline OHA & & Metformin & $\mathrm{PO}$ & 1 \\
\hline TCA & & Amitriptylline & $\mathrm{PO}$ & 1 \\
\hline Local Anaesthetic & & Lignocaine & IV & 1 \\
\hline Antiemetic & & Perinorm & $\mathrm{PO}$ & 1 \\
\hline Others & & Radiocontrast & IV & 2 \\
\hline
\end{tabular}




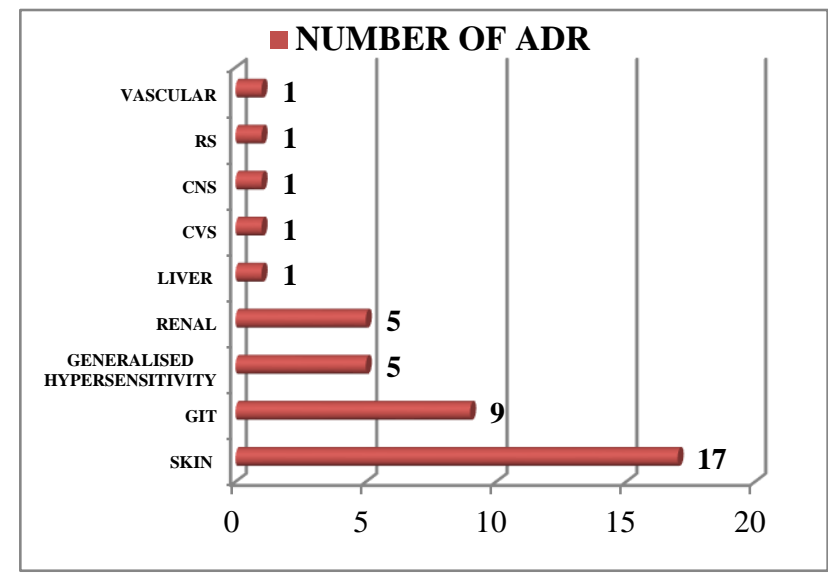

Figure 1: Organ systems affected by ADR.

The suspected therapeutic class of drugs causing ADRs was elaborated in Table 3. It was noted that 55\% of ADRs were caused due to antimicrobials especially cephalosporins (33\%) and 16\% due to NSAID. Anticancer drugs and Enzymes accounted for $14 \%$ of ADR each $7 \%$. Based on the onset of ADR, 32\% were acute ( $<1 \mathrm{hr}), 53 \%$ were subacute (1-24 hrs) and $15 \%$ were latent $(>24 \mathrm{hrs})$. More number of ADR's were from Medicine department (29\%) followed by Surgery (16\%) and OG (16\%) departments (Table 4).

Table 4: Department wise distribution of ADR.

\begin{tabular}{|ll|}
\hline Name of the department & $\begin{array}{l}\text { Number of patients } \\
\text { with ADR (\%) } \\
(\mathbf{n = 3 8 )}\end{array}$ \\
\hline Medicine & $11(29 \%)$ \\
\hline Surgery & $6(16 \%)$ \\
\hline Obstetrics and gynaecology & $6(16 \%)$ \\
\hline Oncology & $3(8 \%)$ \\
\hline Special ward & $3(8 \%)$ \\
\hline Ophthalmology & $2(5 \%)$ \\
\hline Chest medicine & $2(5 \%)$ \\
\hline ENT & $1(3 \%)$ \\
\hline Urology & $1(3 \%)$ \\
\hline Plastic surgery & $1(3 \%)$ \\
\hline Orthopaedics & $1(3 \%)$ \\
\hline Psychiatry & $1(3 \%)$ \\
\hline
\end{tabular}

Among all the reported ADRs with respect to Naranjo's probability scale, $63 \%$ of ADR were evaluated as being probable, $26 \%$ as being possible, and $11 \%$ of ADRs belonged to the definite category. Assessment based on modified Hartwig and Siegel scale showed that $45 \%$ ADRs were categorized as moderately severe, $42 \%$ were of mild severity and $3 \%$ of cases were evaluated as severe. No fatalities due to ADR were recorded in the study. Evaluation based on modified Schumock and Thornton criteria on the preventability of suspected ADR revealed that $58 \%$ of ADRs were probably preventable, $10 \%$ were definitely preventable and $32 \%$ of reported ADRs were not preventable (Table 5).
Table 5: Causality, severity a preventability assessment of ADR.

\begin{tabular}{|c|c|}
\hline \multicolumn{2}{|c|}{ Causality assessment (Naranjo's scale) } \\
\hline Parameters & Number of ADRs (\%) \\
\hline Definite & $4(11 \%)$ \\
\hline Probable & $24(63 \%)$ \\
\hline Possible & $10(26 \%$ \\
\hline Doubtful & 0 \\
\hline \multicolumn{2}{|c|}{$\begin{array}{l}\text { Severity assessment (Modified Hartwig and Seigel } \\
\text { scale) }\end{array}$} \\
\hline Mild & $16(42 \%)$ \\
\hline Moderate & $17(45 \%)$ \\
\hline Severe & $5(3 \%)$ \\
\hline \multicolumn{2}{|c|}{$\begin{array}{l}\text { Preventability assessment (Modified Schumock and } \\
\text { Thorton scale) }\end{array}$} \\
\hline Not preventable & $12(32 \%)$ \\
\hline Probably preventable & $22(58 \%)$ \\
\hline Definitely preventable & $4(10 \%)$ \\
\hline
\end{tabular}

Based on the management of ADR's, cessation of drug was required in $45 \%$ cases, $26 \%$ cases were managed by switching the drugs to another group producing the same therapeutic response and in $29 \%$ the offending drugs were continued without any sequelae (Figure 2). Figure 3 shows the recovery outcomes with ADR. Details regarding recovery outcomes were unknown in $10 \%$ of cases, already recovered in $77 \%$ and recovering in $13 \%$ cases.

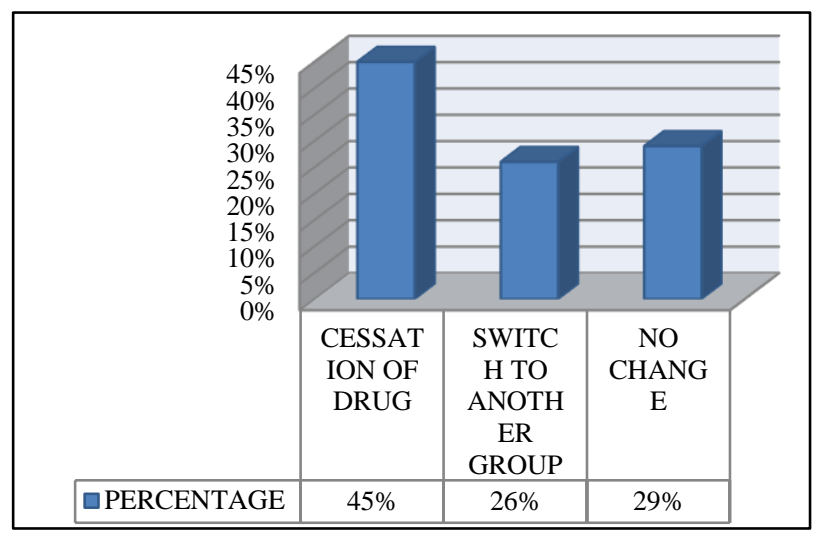

Figure 2: Fate of suspected drugs.

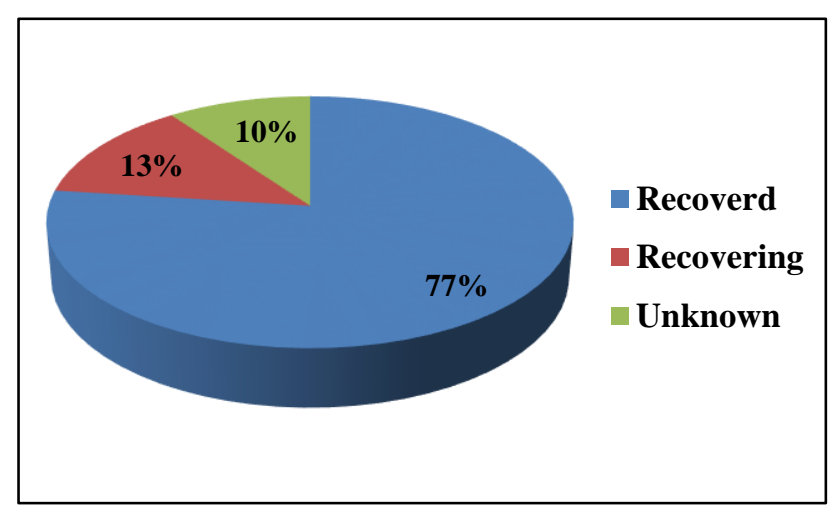

Figure 3: Patient outcomes with ADR. 


\section{DISCUSSION}

The present study revealed the pattern of ADR reported from various departments. Of the 38 patients included in the study, $42 \%$ were in the age group of 19-39 years. This result was in contradiction to various studies which showed increased incidence of ADR among 40-60 yrs., ${ }^{4,7}$ This may be due to the fact this population is attending hospital more frequently and is a major population to receive drug therapy. Male patients were more predisposed to ADRs and a similar pattern of gender distribution was evident in the present study. ${ }^{7-9}$

Skin was the chief organ system affected with most common complaints of skin rashes, which was also observed in various previous studies. ${ }^{10,11}$ Many previous studies including the present study have revealed that antimicrobials are the majority of ADR-causing drugs since they are the most commonly prescribed drugs. ${ }^{12,13}$ Findings documented in the present study were consistent with the previous research which revealed that the major antimicrobial drug causing ADR was cephalosporins, nonsteroidal anti-inflammatory drugs (NSAIDs) was diclofenac as they were the most commonly used drugs in their group.

The maximum number of reports were from medicine department. This is because they rely on drug therapy to the maximum compared to other departments and also patients in this department have multiple co morbidities and therefore prone for drug interactions also. The second departments that contributed to ADRs were surgery and OG. These departments often use large number of antibiotics. Most of the reactions were type $\mathrm{A}$ and therefore predictable. Some of the ADRs were due to extension of pharmacological actions.

The causality assessment of reported ADRs by Naranjo's probability scale showed that most of the (63\%) ADRs were probable, which is consistent with past studies. ${ }^{4,14}$ Rechallenge was not done for most of the patients due to ethical issues and hence we did not get definite relationship. As per Hartwig scale, $45 \%$ of the ADRs were moderate in nature. Patients required discontinuation of offending drug and treatment for ADRs. This was also consistent with previous other studies. ${ }^{15,16}$ The preventability of suspected ADRs assessed by modified Schumock and Thornton criteria showed that $58 \%$ of ADRs were probably preventable, which is in accordance with previous study. ${ }^{4,15}$ In probably preventable ADRs proper precautionary steps were not taken whereas in definitely preventable ADRs, the patients had a previous history of similar reaction following the same drug intake which shows us the lack of awareness.

The fate of the suspected drugs showed that the offending drug was stopped in majority of cases $(45 \%)$ and no change was done in $29 \%$ of cases in view of risk benefit ratio in particular patients. Whereas in $26 \%$ of cases, switch over to another group of drugs were done especially with antibiotics even if the reactions were mild. Dose reduction and rechallenge was not done for any patients. Most of the patients recovered completely since most of the reactions were mild and moderate. There was no fatality due to ADR.

In this study it was observed that the documentation of ADRs were less which could be attributed to lack of knowledge and awareness about the importance of drug safety monitoring, poor knowledge of ADR reporting programme objectives and busy outpatient setting, and many clinicians do not consider reporting a priority. This study suffers the main drawback of spontaneous reporting system i.e. underreporting. Thus, ADR monitoring should be strengthened, and healthcare providers should be encouraged to report more ADRs.

\section{CONCLUSION}

The study concluded that Adverse Drug Reactions are common and some of them resulted in increased healthcare cost due to need of some interventions and increased length of hospital stay. The monitoring and reporting of suspected ADRs by healthcare professionals aids in improved patient welfare. This also acts as an alerting mechanism for physicians. ADRs to drugs happen commonly, and their reporting is important for the early recognition and prevention of ADRs. It not only helps in generating signals but also helps the regulatory authorities in making the policy decision. Furthermore, the awareness about risk factors and in-depth knowledge of the literature of ADRs can help physicians to identify patients with greater risk of ADRs.

\section{Funding: No funding sources Conflict of interest: None declared \\ Ethical approval: The study was approved by the Institutional Ethics Committee}

\section{REFERENCES}

1. Fitzgerald P. Pharmacovigilance inspections. Indian J Pharmacol. 2008 Feb;40(1):S21-3.

2. Medicines: safety of Medicines - Adverse Drug Reactions, Fact sheet; Updated October 2008 Geneva: WHO.

3. Sriram S, Ghasemi A, Ramasamy R, Devi M, Balasubramanian R, Ravi TK, et al. Prevalence of adverse drug reactions at a private tertiary care hospital in south India. Journal of research in medical sciences: The official J of Isfahan Univ of Med Scien. 2011 Jan;16(1):16.

4. Ramakrishnaiah H, Krishnaiah V, Pundarikaksha HP, Ramakrishna V. A prospective study on adverse drug reactions in outpatients and inpatients of medicine department in a tertiary care hospital. Int J Basic Clin Pharmacol. 2015 Jun;4(3):515-21.

5. Pharmacovigilance Programme of India. 2013. Available at: http://www.ipc.nic.in/writereaddata/linkimages/April 
- 2013, \%20PvPIIPC\%20News\%20

Letter,\%20Volume-3,\%20 Issue-5-4537494506.pdf.

6. Kumar A, Majhee L, Gari M. Causality, severity and preventability assessment of adverse drug reactions in patients received anti-retroviral therapy in a tertiary care hospital: A retrospective study. Nat $\mathbf{J}$ of Physiology Phar and Pharmacol. 2017;7:178-82.

7. Rabbur RS, Emmerton L. An introduction to adverse drug reporting system in different countries. Int $\mathbf{J}$ Pharm Pract. 2005;13(1):91-100.

8. Gupta R, Sheikh A, Strachan D, Anderson HR. Increasing hospital admissions for systemic allergic. Increasing hospital admissions for systemic allergic disorders in England: analysis of national admissions data. BMJ. 2003;327:1142-3.

9. Chawla S, Kalra BS, Dharmshaktu P, Sahni P. Adverse drug reaction monitoring in a tertiary care teaching hospital. J Pharmacol Pharmacother. 2011;2(3):196-8.

10. Arulmani R, Rajendran SD, Suresh B. Adverse drug reaction monitoring in a secondary care hospital in South India. Br J Clin Pharmacol. 2008;65(2):210-6.

11. Halkai K, Deshmukh S, Rao VY. An evaluation of adverse drug reactions at ADR monitoring centre in tertiary care hospital. Int $\mathrm{J}$ of Terapeutic Applications. 2016;32:86-9.

12. Vora MB, Tripathi CB. Adverse drug reactions in inpatients of internal medicine wards at a tertiary care hospital: a prospective cohort study. J Pharmacol Pharmacother. 2011;2(1):21-5.

13. Gor AP, Desai SV. Adverse drug reactions in the inpatients of medicine department of a rural tertiary are teaching hospital and influence of pharmacovigilance in reporting ADR. Ind $\mathbf{J}$ Pharmacol. 2008:40(1):37-40.

14. Shrivastava M, Uchit G, Chakravarti A, Joshi G, Mahatme M, Chaudhari $\mathrm{H}$. Adverse drug reactions reported in Indira Gandhi Government Medical College and Hospital, Nagpur. J Assoc Physicians India. 2011;59:296-9.

15. Avery AJ, Anderson C, Bond CM, Fortnum H, Gifford A, Hannaford PC, et al. Evaluation of patient reporting of adverse drug reactions to the UK 'Yellow card scheme': literature review, descriptive and qualitative analyses, and questionnaire surveys. Health Technol Assess. 2011;15(20):1-234.

16. Palanisamy S, Kumaran KS, Rajasekaran A. A study on assessment, monitoring, and reporting of adverse drug reactions in Indian hospital. Asian J Pharm Clin Res. 2011;4(3):112-6.

Cite this article as: Kabilan K, Sathyanarayanan V, Rani RJ. Spectrum of adverse drug reactions and implicated drugs in a tertiary care centre: a prospective study. Int J Basic Clin Pharmacol 2018;7:1345-50. 